\title{
Physiological alterations in wheat during drought stress tolerance at different growth stages
}

\author{
Zahid Akram ${ }^{1 *}$, Qadeer Ahmad ${ }^{1}$, Atta Ullah ${ }^{1,3}$, Ghulam Shabbir ${ }^{1}$, \\ Tallat Mahmood ${ }^{1}$, Zaheer Ahmed ${ }^{2}$ and Zahid Hussain Shah ${ }^{1}$ \\ 1. Department of Plant Breeding and Genetics, PMAS-Arid Agriculture University Rawalpindi, Pakistan \\ 2. Center for Advanced Studies in Agriculture and Food Security (CAS-AFS), University of Agriculture \\ Faisalabad, Pakistan \\ 3. Department of Plant Breeding and Genetics, Balochistan Agriculture College, Quetta, Pakistan \\ *Corresponding author's email: akramzahid@hotmail.com \\ Citation \\ Zahid Akram, Qadeer Ahmad, Atta Ullah, Ghulam Shabbir, Tallat Mahmood, Zaheer Ahmed and Zahid Hussain \\ Shah. Physiological alterations in wheat during drought stress tolerance at different growth stages. Pure and \\ Applied Biology. Vol. 11, Issue 1, pp331-339. http://dx.doi.org/10.19045/bspab.2022.110034

\begin{tabular}{llll}
\hline \hline Received: 09/02/2021 & Revised: 23/04/2021 & Accepted: 27/06/2021 & Online First: 28/07/2021 \\
\hline
\end{tabular}

\section{Abstract}

Wheat is a staple diet for the majority of the people in the world. It is widely adapted and cultivated in diverse environments across the globe. The present study was conducted to identify drought-tolerant genotypes and analyze important physiological alterations that occur during drought stress at different growth and developmental stages. Twenty advanced breeding lines were planted under field condition, and water stress was applied at four developmental stages. Wheat accessions which performed best for studied traits that include 11402 (plant height), 11407, 10932 (stomatal frequency), 11399, and 11451 depicted good results for cell membrane stability, whereas others showed the presence of leaf waxiness. Principal component analysis showed that accession 10929 (V15), 11133 (V4), 11402 (V10) and 11399 (V9) exhibited a positive and strong correlation for plant height, stomatal frequency, cell membrane stability, and proline content, respectively. The identified potential accessions which performed well under water stress condition for various physiological traits could be recommended for future breeding and development of wheat genotypes for rainfed ecologies.

Keywords: Drought; Growth stages; Water stress; Wheat

\section{Introduction}

Wheat (Triticum aestivum $\mathrm{L}$ ) is consumed as a staple food around the globe. Due to adverse and abrupt changes in climate, the summer season duration is increasing each year and the time period for the winter season is decreasing [1]. Under this environmental effect, water is lowering down day by day. Therefore, less groundwater is available for the utilization of crops. Owing to its agricultural importance, wheat is ranked at the top position in the country among all cereals.
According to the economic survey of Pakistan 2017-18, the area under wheat cultivation was 8,734 thousand hectares which has been decreased by $2.6 \%$ as compared to the year 2016-17, when 8,972 thousand hectares were sown. Wheat production was recorded at 25.492 million tons during 2017, which is approximately $4.4 \%$ less as compared to the production of 26.674 million tons last year. Climate change resulted in decreasing the total wheat production as compared to the previous year $[2,3]$. 
Wheat is grown in various regions of the country in irrigated as well as in rainfed areas. The average wheat production is low in rainfed areas as compared to the irrigated areas due to a shortage of water [4]. The level of underground water is declining day by day due to the climate effect. Therefore, water stress affects different stages of wheat crop development and ultimately grain yield decreases sharply [5].

At present, drought has become an alarming issue and there is a need to introduce climate-smart cultivars [6]. Since wheat grown in rainfed areas often faces the drought stress, therefore, it is dire need to develop drought-tolerant varieties that could endure water stress at critical growth stages. However, water is playing an important role in the nourishment of a crop. Underwater shortage conditions, plant growth, and height are decreased before its vegetative and maturity stage [7]. Variants are also varied when it is grown under low water availability. Due to changes in water availability stomatal frequency is also affected between drought-tolerant and susceptible varieties [8, 9]. Stomatal frequency is reduced in drought-tolerant varieties. Cell membrane stability is considered for the evaluation of different wheat cultivars under abiotic stresses like heat tolerant and salt tolerant [10]. Leaf waxiness plays a vital role in decreasing transpiration rate when plants face abiotic stress like heat [11].

Principal component analysis makes it possible to transform a given set of characteristics (variables) that are not mutually correlated into a new system of characteristics [12]. The obtained variables may also be used for further analysis, where the assumption of no co-linearity is required. Moreover, the analysis is characterized by the fact that it includes the total variance of variables, explains the maximum variance within a data set, and is a function of primary variables [13].

Keeping in view the current drought situation in the country, the present study was conducted to evaluate wheat material under water stress conditions on different wheat growth stages. The studied parameters were stomatal frequency, plant height, proline content, cell membrane stability, and leaf waxiness. Moreover, the main objective of this study was to screen the wheat genotypes based on physiological indices using the principal component analysis to estimate the relationship among traits and potential accessions. Thus, the outperforming accessions identified for drought tolerance would serves important genetic sources for improving wheat under different climate scenarios.

\section{Materials and Methods}

This study was carried out in the Department of Plant Breeding and Genetics, PMAS- Arid Agriculture University Rawalpindi, Pakistan. Twenty different wheat accessions were obtained from the National Agriculture Research Centre (NARC) Islamabad, Pakistan. These lines were selected based on the morphology evaluation against low water availability and were recommended for variety development so that these can be commercialized in Pothwar (rainfed) as well as irrigated wheat production areas. Seeds were sown in polythene bags filled with soil, following Completely Randomized Design (CRD). Plants were subjected to water stress at four different growth stages i.e. tillering, heading, booting, and anthesis. Data were recorded regarding different physiological and morphological parameters i.e. plant height, stomatal frequency, leaf waxiness, cell membrane stability, and proline content.

\section{Plant height}

The meter rod was used to measure the height of first primary tiller of wheat plant, and it was recorded in centimeters at the maturity stage. The height of all the five selected plants on the four stages was recorded.

\section{Stomatal frequency}

To record the data of five selected plants at four growth stages for stomatal frequency, a thin polish of salmon pink was used on 
the small portion of the abaxial surface of the flag leaf. One site was selected for each treatment. After the application of nail polish on a leaf, it was kept for about five minutes for air-drying. After the drying of nail polish, cellophane tape was used to peel the polished part and then stuck it on the glass slide. Slides were examined under a compound microscope to count the stomata. These plants were used for data recording at each growth stage.

\section{Cell membrane stability}

Leaf samples were collected from all the wheat genotypes to check the cell membrane stability. About 0.1-g of leaf portion was cut into disc shape pieces in even size. Then, it was placed in the test tube in the form of two sets along with 10 $\mathrm{ml}$ of distilled water. Then, it was kept for 30 mins at $40^{\circ} \mathrm{C}$ first and 15 minutes at $90^{\circ} \mathrm{C}$ in the water bath. A conductivity meter was used to measure their ion leakage and with the help of the Cell membrane stability index (CMS Index), results were calculated. The formula used to measure cell membrane stability is mentioned below:

Cell Membrane Stability index $=\left[1-\left(C_{1}-C_{2}\right)\right] \times 100$

Where $\mathrm{C} 1$ is stability index at $40^{\circ} \mathrm{C}$ and $\mathrm{C}_{2}$ is stability index at $90^{\circ} \mathrm{C}$.

\section{Proline content}

To calculate the proline content of different wheat genotypes $0.1 \mathrm{~g}$ leaf samples were collected from five selected plants. Then collected plant leaves were grounded in a 5 $\mathrm{ml}$ solution (made up of $3 \%(\mathrm{w} / \mathrm{v})$ homogenized mixture and sulphuric acid). To separate leaf debris, it was put in the centrifuge so that all extracts can be collected. The $2 \mathrm{ml}$ of leaf extracts were kept in a dry test tube and $2 \mathrm{ml}$ of ninhydrin with $2 \mathrm{ml}$ glacial acetic acid were added to it. The mixture of two samples was kept in a hot water bath at $100^{\circ} \mathrm{C}$ for one hour. After this, these test tubes were kept in the icebox to stop the reaction. After this, $4 \mathrm{ml}$ of toluene and the mixture were added and stirred even chromophore layer was obtained. To record proline content, chromosome absorption was determined at 520 nanometers by a spectrometer, and Toluene utilizing as a bank. Thus, proline concentration was recorded by making a standard curve.

\section{Leaf waxiness}

The data was observed through rubbing of leaves with the hand under the condition of presence or absence of a waxy layer on the flag leaf.

\section{Statistical analysis}

The experiment was performed by following a complete randomized design (CRD). Analysis of variance (ANOVA) was computed using computer software SPSS Ver.22 IBM. Pair-wise Means were compared by least significant difference (LSD) test. The principal component analysis was used to estimate the relationship between accessions and studied traits [14].

\section{Results and Discussion}

Water stress treatment was given at tillering, booting, heading, and anthesis stages, along with a control treatment. The recorded results revealed that these genotypes were significantly varied in the term of drought tolerance. The accession materials used in present research are listed in (Table 1).

\section{Plant height}

The analysis of variance showed that plant height in all treatments was significantly affected by water stress and genotypes depicted the variations in plant height. The plant height of all accessions revealed variations in their performance (Fig. 1; Table 2). The mean of plant height in accessions in control (T0) ranged from 65.8 to $39.0 \mathrm{~cm}, 59.3$ to $28.0 \mathrm{~cm}$ in $\mathrm{T} 1,63.9$ to $31.6 \mathrm{~cm}$ in $\mathrm{T} 2$ and 64.8 to $38.6 \mathrm{~cm}$ in $\mathrm{T} 3$. Wheat genotype 11402 (V10) showed maximum average plant height whereas the genotype 10936 (V19), 10937 (V20) and 10935 (V19) revealed minimum plant height under water stress treatments T1, T2 and T3, respectively. The genotype 10935, 10936, and 10937 were affected by water stress $[15,16]$. They showed that water stress decreases the plant height when it 
reaches to vegetative and maturity stages. According to Ahmed et al. [17] plant height is positively contributed to the vegetative growth and grain yield.

\section{Stomatal frequency}

The analysis of variance showed highly significant results for stomatal frequency in all wheat genotypes. The treatments revealed that a significant variation was recorded in all wheat genotypes under water stress conditions (Fig. 2; Table 3). The mean stomatal frequency ranged for wheat genotypes was noticed in accession 11407 (V6) and 10929 (V15) which were appeared to have a lower number of stomata under water stress treatments as compared to the control treatment. Previous study results depicted that stomatal frequency is reduced on the leaves by water stress conditions as compared to drought susceptible genotypes [18].

\section{Cell membrane stability}

Cell membrane stability was observed based on cell membrane injury. The analysis for the CMS revealed that all genotypes were significantly affected by water stress treatments (Fig. 3; Table 4). The percent injury ranged was between 0.72 to $0.9,0.86$ to $0.73,0.87$ to $0.64,0.91$ to 0.75 in $\mathrm{T} 0, \mathrm{~T} 1, \mathrm{~T} 2$, and $\mathrm{T} 3$ respectively. Results were derived from LSD indicated two accession 10932 (V17) and 11399 (V9) having minimum percent injury but 11134 (V5) and 11135 (V6) had a high percent injury. Earlier study on wheat pointed out that percent injury due to water stress was high while variations in terms of cytoplasmic male sterility, which was very low among all wheat genotypes [19].

\section{Proline contents}

The mean difference values for proline concentration revealed that diversity is present among the wheat germplasm genotypes (Fig. 4; Table 5). The wheat genotypes 10928 showed low concentration for proline content while accession 11451 showed maximum proline contents. All wheat genotypes confirmed different amounts of proline content under water stress conditions. The analysis of variance (ANOVA) represented that wheat genotypes were highly significantly affected by water stress treatments. The four treatments showed significant results in both levels of significance. Previous study revealed that wheat treatments on different growth stages are significantly affected by water stress [20].

\section{Leaf waxiness}

Leaf waxiness was recorded based on the presence or absence of a wax layer on wheat flag leaves. The genotypes 11133 (V4), 10927 (V13), 10932 (V17) and 10937 (V20) had no wax deposition on their leaves, while the genotype 10842 (V2), 11030 (V3), 11369 (V7), 11398 (V8), 11399 (V9) and 10935 (V18) had no waxiness on their flag leaves. The rest of the ten wheat genotypes appeared to have waxiness on the flag leaf surface area and comparatively performed better under water stress conditions (Fig. 5; Table 6). Presence of waxiness on leaves is beneficial for water storage and prevent water loss from their leaves. Those genotypes have lack of wax layer are considered susceptible under less water availability. Evaluating drought tolerance in wheat, earlier results described that the wheat genotypes which have maximum proline contents would respond better under water stress as compared to water stress susceptible genotypes [8]

\section{Principal component analysis}

Principal component analysis (PCA) partitioned the total variance into four principal components (PCs), contributing to the total diversity among the studied traits. Four PCs suggested the extent of trait's contribution towards genetic variability underwater stress conditions, in respect of positive and negative loads. In this study, PC1 contributed $30.92 \%$ to overall variability and it contained mostly water stress-related traits but some physiological traits as well. However, PC2 contained $27.61 \%$ of the total variability. In short, all the components showed good results for important principal components. In case of bi-plot the genotypes which are 
nearer to the center have high and positive correlation as compared to those which are far from others, with high genetic variability. However, loading values which are more than zero are considerable for further screening instead loads less than zero are reflecting negative consideration. For main PC1, studied traits including plant height (PH), cell membrane stability (CMS) and proline content (PC) exhibited as main constituents with positive loads for genetic variability. While in PC2 Plant height, stomatal frequency and proline content depicted the positive load for genetic variability. In PC3 proline content depicted the positive type of genetic variability. As for PC4 stomatal frequency, cell membrane stability and proline content exhibited a positive type of genetic variability. Several studies estimated the diversity of wheat germplasm using multivariate analysis and screened out most diverse accession using physio-morphic traits [4]. Principal component analysis also evident for exploring genetic divergence in wheat and other field crops primarily for selecting desirable genotypes $[12,21,22]$.

Table 1. List of wheat genotypes acquired from NARC Islamabad

\begin{tabular}{|c|c|c|c|}
\hline Var. Code & Genotype Number & Var. Code & Genotype Number \\
\hline V1 & 10760 & V11 & 11407 \\
\hline V2 & 10842 & V12 & 11451 \\
\hline V3 & 11030 & V13 & 10927 \\
\hline V4 & 11133 & V14 & 10928 \\
\hline V5 & 11134 & V15 & 10929 \\
\hline V6 & 11135 & V16 & 10931 \\
\hline V7 & 11367 & V17 & 10932 \\
\hline V8 & 11398 & V18 & 10935 \\
\hline V9 & 11399 & V19 & 10936 \\
\hline V10 & 11402 & V20 & 10937 \\
\hline
\end{tabular}

Table 2. Mean squares, Grand mean and CV \% for plant height under T0, T1, T2 and T3

\begin{tabular}{|c|c|c|c|c|c|}
\hline SOV & DF & T0 & T1 & T2 & T3 \\
\hline Accessions & 19 & $140.4^{* *}$ & $147.3^{* *}$ & $227.6 * *$ & $169.4^{* *}$ \\
\hline Error & 40 & 16.4 & 14.7 & 16.1 & 10.6 \\
\hline Grand Mean & & 49.97 & 45.45 & 46.11 & 50.75 \\
\hline CV \% & & 8.10 & 8.43 & 8.70 & 6.40 \\
\hline
\end{tabular}

$\mathrm{SOV}=$ Source of variance, $\mathrm{DF}=$ Degree of freedom $\mathrm{T} 0=$ Tillering stage, $\mathrm{T} 1=$ Heading stage, $\mathrm{T} 2=$ Booting stage, $\mathrm{T} 3=$ Anthesis growth stage. All the accessions depicted high significant results for plant height under different treatments

Table 3. Mean squares, Grand mean and CV \% for stomatal frequency under T0, T1, T2 and T3 treatments of wheat genotypes

\begin{tabular}{|c|c|c|c|c|c|}
\hline SOV & DF & T0 & T1 & T2 & T3 \\
\hline Accessions & 19 & $45.31^{* *}$ & $17.99 * *$ & $21.92 * *$ & $8.75^{* *}$ \\
\hline Error & 40 & 2.95 & 2.10 & 1.90 & 1.71 \\
\hline Grand Mean & & 15.13 & 13.36 & 14.70 & 12.98 \\
\hline CV \% & & 11.35 & 10.84 & 10.84 & 10.09 \\
\hline
\end{tabular}

$\mathrm{SOV}=$ Source of variance, $\mathrm{DF}=$ Degree of freedom $\mathrm{T} 0=$ Tillering stage, $\mathrm{T} 1=$ Heading stage, $\mathrm{T} 2=$ =Booting stage, $\mathrm{T} 3=$ Anthesis growth stage. All the accessions depicted high significant results for stomatal frequency under different treatments 
Table 4. Mean squares, Grand mean and CV \% for cell membrane stability under T0, T1, T2 and T3 treatments of wheat genotypes

\begin{tabular}{|c|c|c|c|c|c|}
\hline SOV & DF & T0 & T1 & T2 & T3 \\
\hline Accessions & 19 & $0.006^{* *}$ & $0.004^{* *}$ & $0.014 \% \%^{* *}$ & $0.006^{* *}$ \\
\hline Error & 40 & 0.0005 & 0.0003 & 0.0001 & 0.0001 \\
\hline Grand Mean & & 0.82 & 0.80 & 0.79 & 0.84 \\
\hline CV \% & & 2.77 & 2.01 & 1.29 & 1.31 \\
\hline
\end{tabular}

$\mathrm{SOV}=$ Source of variance, $\mathrm{DF}=$ Degree of freedom $\mathrm{T} 0=$ Tillering stage, $\mathrm{T} 1=$ Heading stage, $\mathrm{T} 2=$ Booting stage, $\mathrm{T} 3=$ Anthesis growth stage

Table 5. Mean squares, Grand mean and CV \% for proline content under T0, T1, T2 and T3 treatments of wheat genotypes

\begin{tabular}{|c|c|c|c|c|c|}
\hline SOV & DF & T0 & T1 & T2 & T3 \\
\hline Accessions & 19 & $1.27^{* *}$ & $0.27^{* *}$ & $0.905^{* *}$ & $1.033^{* *}$ \\
\hline Error & 40 & 0.00017 & 0.00019 & 0.00052 & 0.00099 \\
\hline $\begin{array}{c}\text { Grand } \\
\text { Mean }\end{array}$ & & 1.26 & 0.75 & 1.34 & 1.06 \\
\hline CV\% & & 1.04 & 1.85 & 1.70 & 2.93 \\
\hline
\end{tabular}

$\mathrm{SOV}=$ Source of variance, $\mathrm{DF}=$ Degree of freedom $\mathrm{T} 0=$ Tillering stage, $\mathrm{T} 1=$ Heading stage, $\mathrm{T} 2=$ Booting stage, $\mathrm{T} 3=$ Anthesis growth stage

Table 6. Measurement of leaf waxiness on wheat germplasm

\begin{tabular}{|c|c|c|c|c|c|}
\hline Var. No. & Genotypes No. & T0 & T1 & T2 & T3 \\
\hline V1 & 10760 & + & + & + & + \\
\hline V4 & 11133 & - & - & - & - \\
\hline V5 & 11134 & + & + & + & + \\
\hline V6 & 11135 & + & + & + & + \\
\hline V10 & 11402 & + & + & + & + \\
\hline V11 & 11407 & + & + & + & + \\
\hline V12 & 11451 & + & + & + & + \\
\hline V13 & 10927 & - & - & - & - \\
\hline V14 & 10928 & + & + & + & + \\
\hline V15 & 10929 & + & + & + & + \\
\hline V16 & 10931 & - & - & - & - \\
\hline V17 & 10932 & - & - & - & - \\
\hline V19 & 10936 & + & + & + & + \\
\hline V20 & 10937 & + & + & + & + \\
\hline
\end{tabular}

+ Presence of wax on leaves

- Absence of wax on leaves 


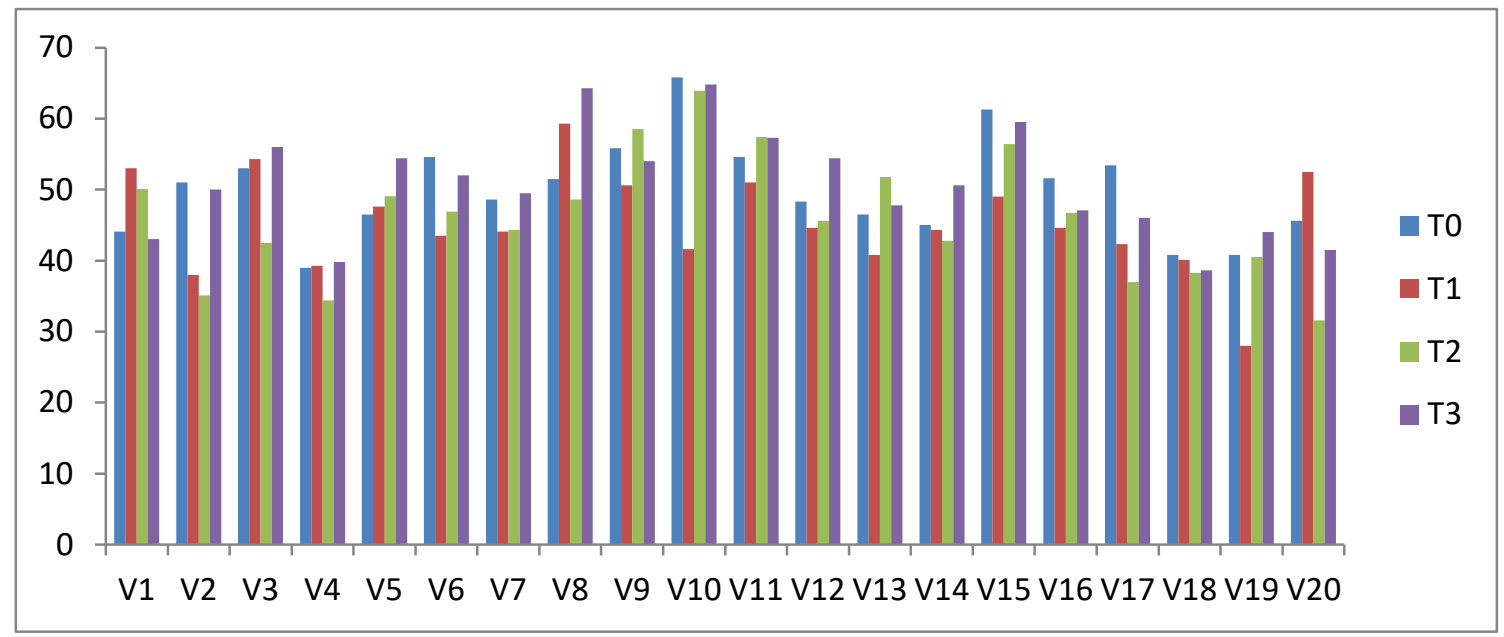

Figure 1. Plant height was significantly affected by different growth stages. $\mathrm{T} 0=$ tillering stage, $T 1=$ heading stage, $T 2=$ booting stage, $T 3=$ anthesis stage

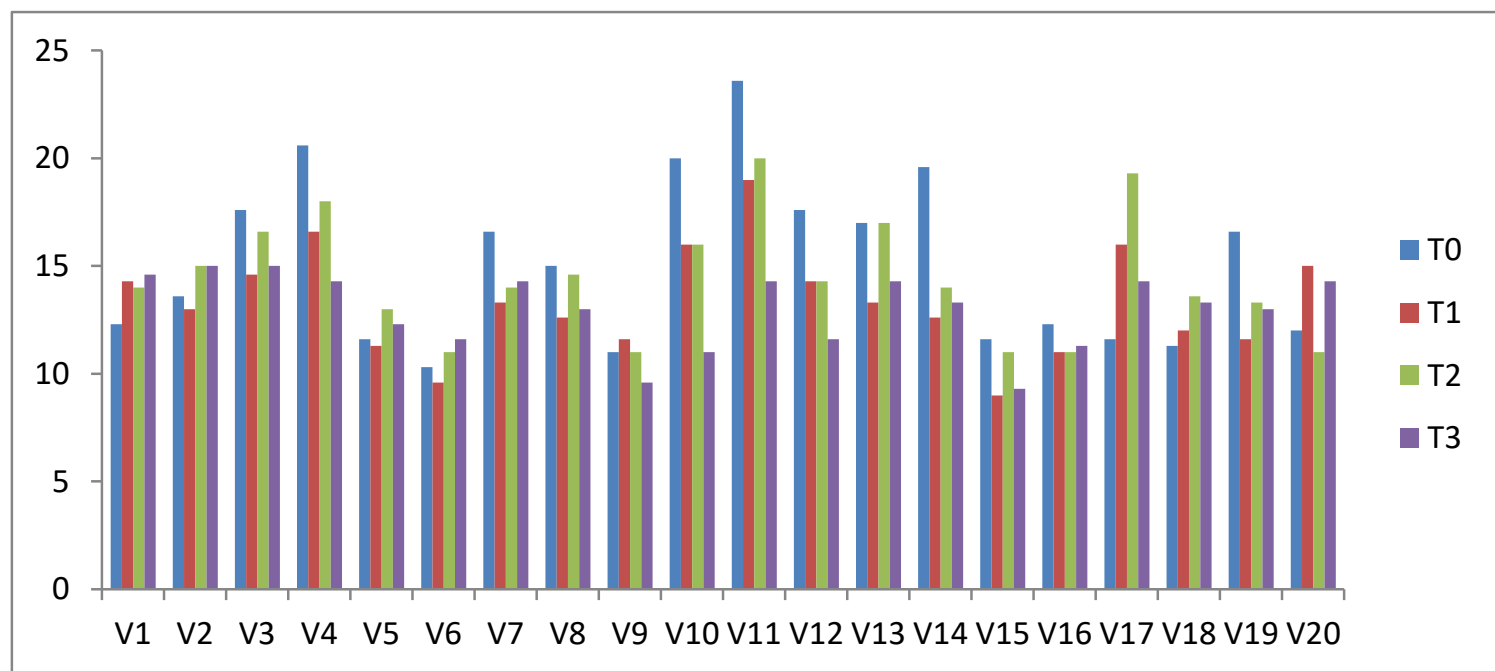

Figure 2. Stomatal frequency was significantly affected by different growth stages. $T 0=$ tillering stage, $\mathrm{T} 1=$ heading stage, $\mathrm{T} 2=$ booting stage, $\mathrm{T} 3=$ anthesis stage

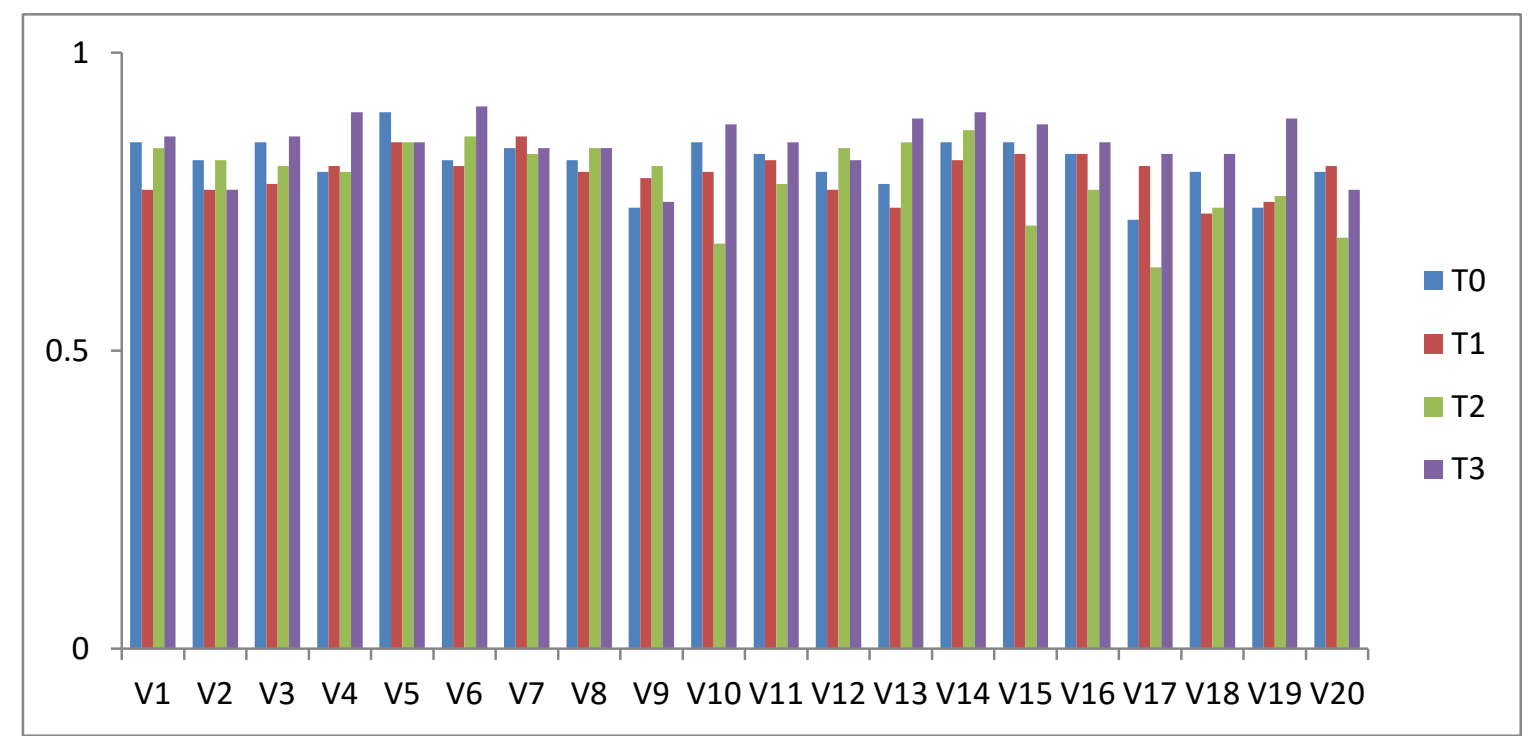

Figure 3. Cell membrane stability was significantly affected by different growth stages. $\mathrm{T} 0=$ tillering stage, $\mathrm{T} 1=$ heading stage, $\mathrm{T} 2=$ booting stage, $\mathrm{T} 3=$ anthesis stage 


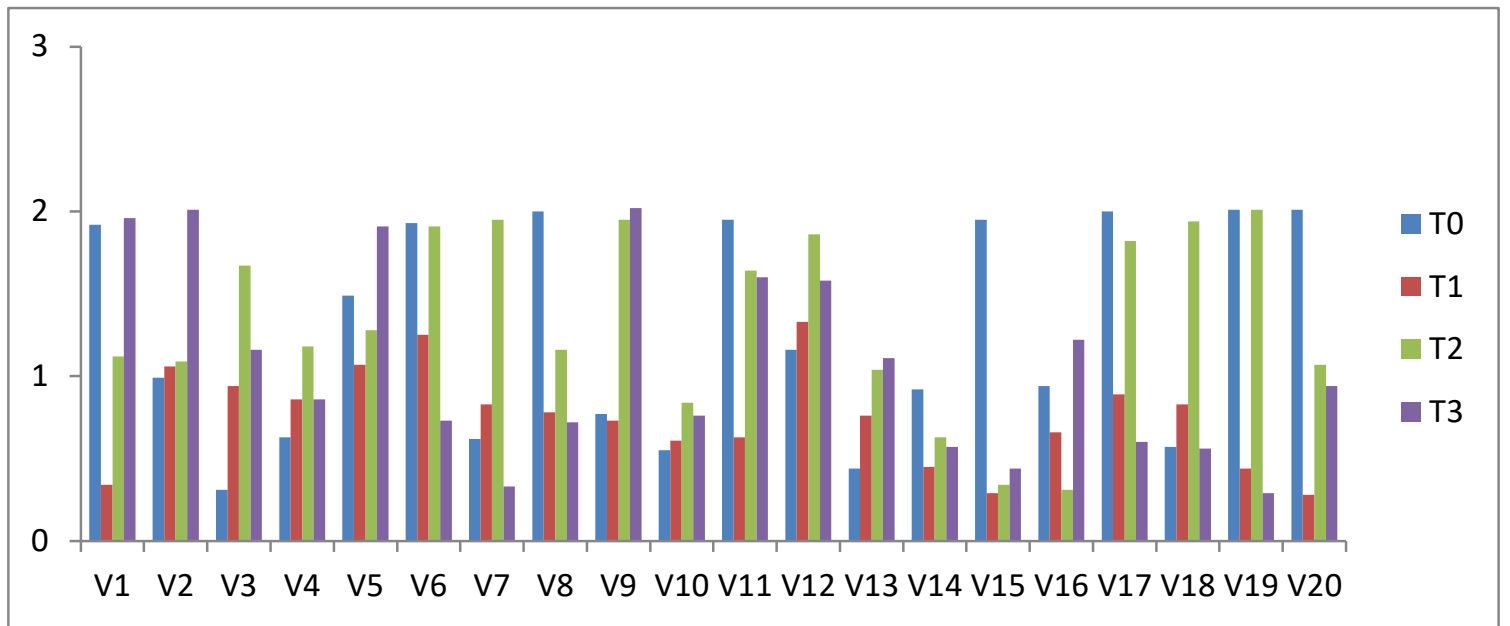

Figure 4. Proline content was significantly affected by different growth stages. $T 0=$ tillering stage, $\mathrm{T} 1=$ heading stage, $\mathrm{T} 2=$ booting stage, $\mathrm{T} 3=$ anthesis stage

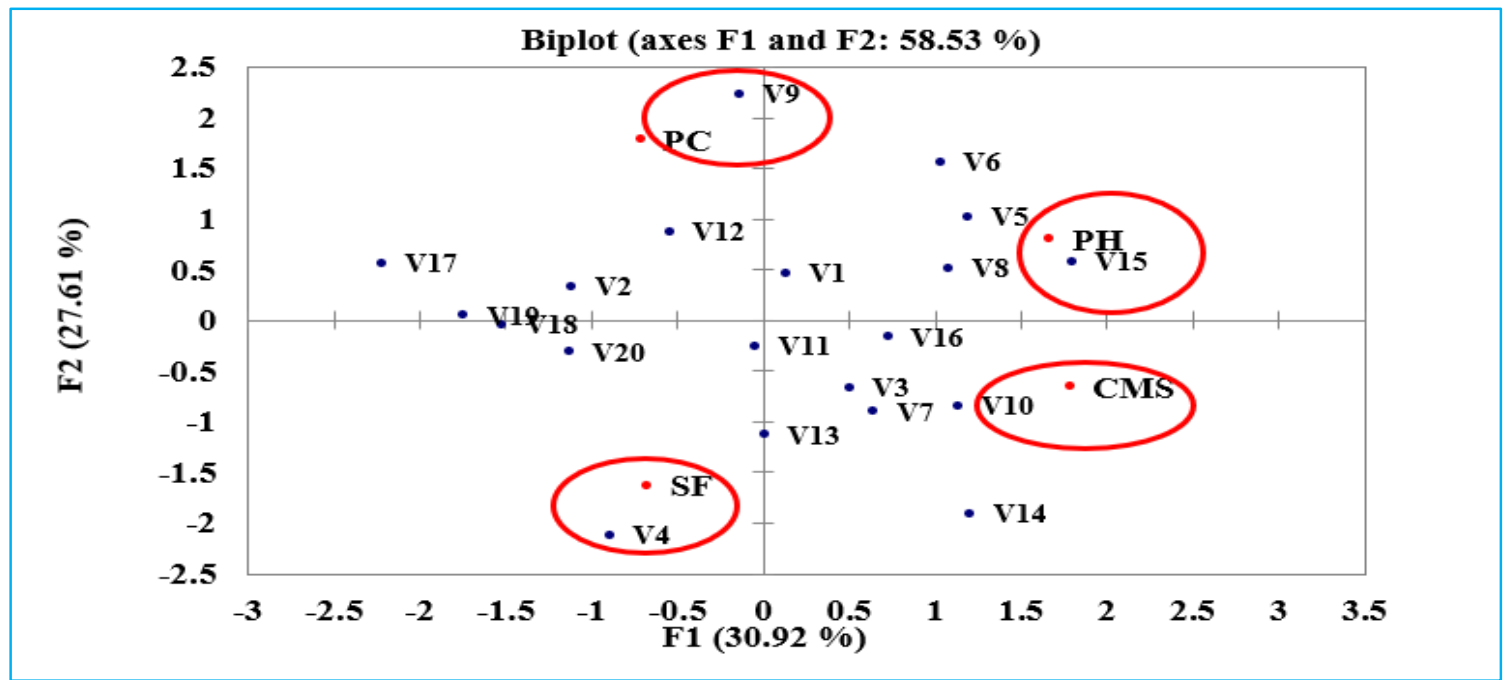

Figure 5. PCA bi-plot indicated the maximum genetic diversity for physiological traits and water stress stable genotypes

\section{Conclusion}

The present study indicated that wheat has the ability to tolerate under water stress conditions. Wheat genotype 11402 (V10) performed best for plant height, genotype 11407 (V11) has a maximum stomatal frequency, genotype 10932 (V17) and 11399 (V9) and 11399 (V9) showed the best result for cell membrane stability. Genotype 11451 exhibited maximum proline content. Whereas ten wheat accession naming 10760 (V1), 11134 (V5), 11135 (V6), 11402 (V10), 11407 (V11), 11451 (V12), 10928 (V14), 10929 (V15), 10936 (V19) and 10937 (V20) appeared to have leaf waxiness under stress treatments which helped to overcome stress conditions and performed better. PCA analysis demonstrated that the genotypes 10929 (V15), 11133 (V4), 11402 (V10) and 11399 (V9) appeared to be most diverse and high performer for one or more traits. Hence, it is concluded that these genotypes have maximum genetic variability and potential to survive under different climate scenarios of water shortage.

\section{Authors' contributions}

Conceived and designed the experiments: $\mathrm{Z}$ Akram, Performed the experiments: Q Ahmad \& A Ullah, Analyzed the data: T Mahmood, Contributed materials/ analysis/ tools: G Shabbir \& Z Ahmed, Wrote the paper: Q Ahmad, A Ullah \& ZH Shah.

\section{References}

1. Gornall J, Betts R, Burke E, Clark R, Camp J, Willett K \& Wiltshire A (2010). Implications of climate change for agricultural productivity in the early twenty-first century. Philos Trans $R$ Soc B 365(1554): 2973-2989. 
2. Pakistan Economic Survey (2017-18). Ministry of Finance. Government of Pakistan, Islamabad, Pakistan.

3. Elham F, Nejad RAK, Salekdeh GH \& Najafi F (2012). Evaluation of cultivar wax deposition, stomata and carbohydrate of wheat leaves for screening drought tolerance. Adv Environ Biol 6(13): 40354040.

4. Qaseem MF, Qureshi R, Illyas N \& JalalUd-Din SG (2017). Multivariate statistical analysis for yield and yield components in bread wheat planted under rainfed conditions. Pak J Bot 49(6): 2445-2450.

5. Raza MA, Ahmad HM, Akram Z \& Ali Q (2015). Evaluation of wheat (Triticum aestivum L.) genotypes for morphological traits under rainfed conditions. Acad Are 7(9): 217-221.

6. Yousafzai MNK (2007). Evaluation on anatomal and morphological traits in relation to lower water requirement condition of bread wheat (Triticum aestivum L.). Pak J Bot 39(7): 2725-2731.

7. Zhao W, Liu L, Shen Q, Yang J, Han X, Tian F \& Wu J (2020). Effects of water stress on photosynthesis, yield, and water use efficiency in winter wheat. Water 12(8): 2127.

8. Bano AS \& Aziz NA (2003). Salt and drought stress in wheat and the role of absicicacid. Pak J Bot 35(5): 871-884.

9. Aown, M, Raza S, Saleem MF, Anjum SA, Khaliq T \& Wahid MA (2012). Foliar application of potassium under water deficiet condition improved the growth and yield of wheat (Triticum aestivum L). $J$ Anim Plant Sci 22(2): 431-437.

10. Baloch MJ, Dunwell J, Khakwani AA, Dennett M, Jatoi WA \& Channa SA (2012). Assessment of wheat cultivars for drought tolerance via osmotic stress imposed at early seedling growth stages. J Agri Res 50(3): 299-310.

11. Blum A, Klueva N \& Nguyen HT (2001). Wheat cellular thermotolerance is related to yield under heat stress. Euphytica 117(2): 117-123.

12. Ullah A, Akram Z, Malik SI \& Khan KSU (2021). Assessment of phenotypic and molecular diversity in soybean [Glycine max (L.) Merr.] germplasm using morphobiochemical attributes and SSR markers. Genet Resour Crop Evol 1-21.
13. Ghandi A (2013). Principal component analysis and determination of the selection criteria in bread wheat (Triticum aestivum L.) genotypes. Int J Agri Crop Sci 5(18): 2024-2027.

14. Steel RG \& Torrie JH (1986). Principles and procedures of statistics: a biometrical approach. $3^{\text {rd }}$ Ed., McGraw Hill Book Co., New York, USA.

15. Sial MA \& Laghari KA (2012). Genetic improvement of drought tolerance in semidwarf wheat. Science Technology and Development. Sci Tech dev 31(4): 335-340.

16. Shafeeq S \& Zafar Y (2006). Genetic variability of different wheat (Triticum aestivum L.) genotypes/cultivars under induced water stress. Pak J Bot 38 (5): 1671-1678.

17. Ahmad Q, Akram Z, Shabbir G, Ijaz SS, Ullah A, Rasool G, Naeem M \& Ilyas M (2019). Estimation of genetic variability among different soybean genotypes for yield and quality traits under the agroclimatic condition of Rawalpindi-Pakistan. Pure Appl Biol 8(1): 762-767.

18. Baloch MJ, Dunwell J, Khakwani AA, Dennett M, Jatoi WA \& Channa SA (2012). Assessment of wheat cultivars for drought tolerance via osmotic stress imposed at early seedling growth stages. J Agri Res 50(3): 299-310.

19. Iftikhar H, Ghori Z, Ali SH, Sheikh S \& Gul A (2019). Wheat responses to stress and biotechnological approaches for improvement. Wheat production in changing environments, Singapore: Springer, 343-392.

20. Singh TP, Kumari J, Yadav R \& Prakesh P (2014). Effect of drought and high temperature on physiological traits and wheat production. Adv Plant Physiol 15 (1): 147-156.

21. Al-Naggar AM, Shafik MM \& Musa RY (2020). Genetic diversity based on morphological traits of 19 maize genotypes using principal component analysis and GT biplot. Annu Res Rev Biol 35 (2): 68-85.

22. Rasool G, Ullah A, Jan A, Waris M, Tariq MA, Ahmad Q (2021). Morphological evaluation of wheat genotypes for grain yield under arid environment of Balochistan. Pure Appl Biol 10(4): 14411449. 